\title{
G4 - Avaliação tecnológica das tendências de apresentações e embalagens de vacinas para programas de imunização indica- das pela OMS
}

Gisele Corrêa Miranda ${ }^{1}$; Luiz Fernando Carvalho ${ }^{1 *}$; IsabellaManjud Maluf ; Celso Farias Crespo ${ }^{1}$; Paulo Roberto Gomes dos Santos ${ }^{1}$.

\section{1- Bio-Manguinhos/Fiocruz}

\section{Introdução:}

As vacinas ofertadas mundialmente estão passando por acelerada inovação alterando a quantidade de produtos ofertados e utilizados nos Programas Nacionais de Imunização, modificando as características de apresentação e os valores destes produtos por dose. Estas mudanças levaram à necessidade de alteração nas características, controles e investimento em rede de frio dos Programas de Imunização para armazenar e distribuir esses imunobiológicos em segurança. A Organização Mundial de Saúde (OMS), ciente desses novos desafios relacionados à logística de vacinas, criou um grupo consultivo que desenvolveu um estudo sobre harmonização de embalagem e que serviu de base para recomendações de Harmonização das Embalagens indicadas no documento "generic Preferred Product Profile" (gPPP) para pré-qualificação de vacinas. Estas recomendações foram estudadas pela Comunidade de Prática de Embalagem e Logística (CoP-PackLog) de Bio-Manguinhos, que se encontra em reuniões regulares para analisar desafios e soluções relacionadas à embalagem e logística no âmbito de Bio-Manguinhos.

\section{Objetivo:}

O objetivo do estudo foi fazer uma avaliação tecnológica multidisciplinar dos impactos positivos e negativos das recomendações de embalagem do gPPP e do trabalho de harmonização de embalagem da OMS.

\section{Metodologia:}

O grupo fez uma análise de revisão bibliográfica, utilizando como base as recomendações de harmonização das embalagens indicadas nas características gerais de apresentação dos produtos (generic Prefferred Product Profile gPPP) para pré-qualificação de vacinas na OMS. A partir desta revisão inicial, o grupo realizou entrevistas não estruturadas a fornecedores de materiais de 
embalagem, equipamentos e usuários das vacinas, que serviram de base para as discussões e brainsrtorming conduzidas na Comunidade de Prática de Embalagem e Logística (CoP-PackLog), que gerou um documento único com todas as informações compiladas e analisadas.

\section{Resultados:}

Para cada um dos tópicos do gPPP foram identificadas tanto as restrições e desafios, como as vantagens e oportunidades do atendimento às recomendações, separando em dois cenários possíveis: adequação das instalações atuais do campus Manguinhos (DEPFI) ou adoção apenas para o novo site de produção de Santa Cruz, conhecido como CIBS, atual Projeto NCPFI. O relatório gerado pelo grupo é um compilado de pareceres, comentários e opiniões dos participantes da PackLog sobre as recomendações de harmonização de embalagem da OMS, considerando-se a experiência e a multidisciplinaridade do grupo.

\section{Conclusão:}

$\mathrm{O}$ grupo chegou à conclusão de que as recomendações de harmonização das embalagens de vacinas propostas pela OMS são, em geral úteis tanto para os fabricantes de vacinas quanto para os compradores e usuários delas, apesar de gerar mais esforços das indústrias para viabilizar a adequação e que os principais desafios para adequação estão nas indústrias que ainda não utilizam os frascos DIN, como é o caso de Bio-Manguinhos.

Palavras-Chave: Embalagem; Apresentação de vacinas; Programas de Imunização. 